\title{
Neuro-Fuzzy Modeling of Heat Recovery Steam Generator
}

\author{
A. Ghaffari, A. Chaibakhsh, and S. Shahhoseini
}

\begin{abstract}
In this paper, an application of dynamic neuro-fuzzy systems is presented for modeling the subsystems of the heat recovery steam generator (HRSG). The dynamic neuro-fuzzy models were developed based on the formal NARX models topology. The clustering techniques were employed to define the structure of the fuzzy models by dividing the entire operating regions into smaller subspaces. The optimal cluster centers and corresponding membership functions are captured by FCM, where the parameters of consequent were adjusted by recursive LSE method. A comparison between the responses of the proposed models and the responses of the plants ware preformed, which validates the accuracy and performance of the modeling approach.
\end{abstract}

Index Terms-Power plant, HRSG boiler, fuzzy system, experimental data, clustering technique.

\section{INTRODUCTION}

In recent years, many different modeling approaches have been employed to describe the nonlinear dynamics of power plant subsystems. The analytical models can be developed based on the fundamental laws of physics such as mass conservation, momentum, and energy semi-empirical laws for heat transfer and thermodynamic state relations [1]. In order to develop such analytical models, it is necessary to calibrate the model parameters with respect to boundaries, inputs, and outputs in steady state and transient conditions [2].

The collected Input/output data from field experiments can also be used to develop mathematical models based on identification techniques. There is a vast collection of black-box modeling techniques which are developed for the class of nonlinear systems. In this regard, artificial neural networks (ANN), fuzzy logic (FL) models or a combination of these approaches such as adaptive neuro-fuzzy inference systems (ANFIS) are extensively used for modeling the industrial processes including power plants. This can be addressed in the works done by Afzalian and Linkens (2000), Liu et al. (2003), Sanchez-Lopez et al. (2004), Vieira et al. (2004), Zhang et al. (2006), Ghaffari et al. (2008), and Mastacan et al. (2009) [3]-[7].

If adequate information from the plant performances can be captured, using neuro-fuzzy system would be an appropriate approach to describe the non-linear systems behaviors. One of the most common structures employed for this propose is ANFIS, in which the fuzzy if-then rules are

Manuscript received September 07, 2012; revised November 8, 2012

A. Ghaffari is with the Department of Mechanical Engineering at the K.N Toosi University of Technology, Tehran, Iran (e-mail: ghaffari@kntu.ac.ir).

A. Chaibakhsh is with the Department of Mechanical Engineering at the University of Guilan, Rasht, Guilan, Iran. (e-mail: chaibakhsh@guilan.ac.ir)

S. Shahhoseini is with the South Tehran Brach, Islamic Azad University, Tehran, Iran (e-mail: sajjad.shahhoseini@gmail.com). represented in a network structure. The learning techniques for neural network can be applied in order to tune the parameters of the fuzzy models [8].

In ANIFS structure presented by Jang (1999), the number of fuzzy rules is equal to the product of number of membership functions and the number of inputs [9]. In some cases, the required number of fuzzy rules to cover entire input spaces is very large, which causes the training process becomes time consuming or practically impossible. In order to reduce the number of fuzzy rules without accuracy losses, the fuzzy c-means (FCM) clustering approach was proposed to define the structure of fuzzy systems [10].

In this paper, a combination of fuzzy c-means clustering and least square techniques are employed to identify the parameters of membership functions and fuzzy rules in a multi-input single-output (MISO) TSK type fuzzy inference systems (FIS). The FCM clustering is first employed to extract the number of fuzzy rules and membership functions for the antecedents. Then, the parameters of consequents are defined for model based on a given set of input/output data. The accuracy of developed models is validated by performing a comparison between the responses of developed models and the experimental data.

In next section, a brief description of the plant that consists of a general view of the power plant and its subsystems is presented. Inputs and outputs to the subsystems are also specified in this section. The neuro-fuzzy model based on the experimental data and structure of recurrent model and simulation result is presented in Section IV. In addition, a comparison between the responses of the proposed models with the responses of the real plant is presented to validate the accuracy of the developed models.

\section{System Description And Its Subsystems}

In this study, a HRSG boiler of the combined cycle units at Neka power plant (at the north of Iran) is considered for investigation. This plant consists of two gas turbine units and one steam turbine, which was constructed by Siemens $\mathrm{AG}^{\circledR}$; in 1990. The rated power of gas and steam units are $2 \times 136$ $M W$ and $160 M W$, respectively.

In combined cycle power plants, the exhausted gas from gas turbines is recovered by HRSG. The required heat for this boiler is provided by the hot exhaust gas and three auxiliary burners. The output temperature of gas turbine is about $530^{\circ} \mathrm{C}$, which burns natural gas as the main fuel. The HRSG boiler consists of different parts such as de-aerator, economizer, low-pressure (LP) drum, high-pressure (HP) drum, evaporators, superheaters, and de-superheaters.

The outlet water from condensation system heads to the deaerator, and then is send to the feedwater pump to increase the feedwater pressure. A part of feedwater goes to low 
pressure drum, where its output pressure and temperature are about $0.85 \mathrm{MPa}$ and $235^{\circ} \mathrm{C}$, respectively. The evaporated steam goes to the LP superheater, and then enters to the LP steam turbine section. The other portion of feedwater is pumped to the HP economizer and then goes to HP drum to convert to steam. The steam temperature at the drum header is $300^{\circ} \mathrm{C}$ and its pressure is about $9 M P a$. The evaporated steam goes to the primary and final HP superheaters. This steam with the temperature of $520^{\circ} \mathrm{C}$ and pressure of $9 \mathrm{MPa}$ is flashed to the HP stages of steam turbine. The different components of this HRSG boiler are shown in Fig 1.

Feedwater outlet from condensation system with $75 \mathrm{~kg} / \mathrm{s}$ mass flow rate and temperature about $52^{\circ} \mathrm{C}$ after a chemical treatment stage, goes to the deaerator. In the deaerator, the gas phase is extracted from the liquid phase, which is sent to the feedwater pump and the cycle is repeated.

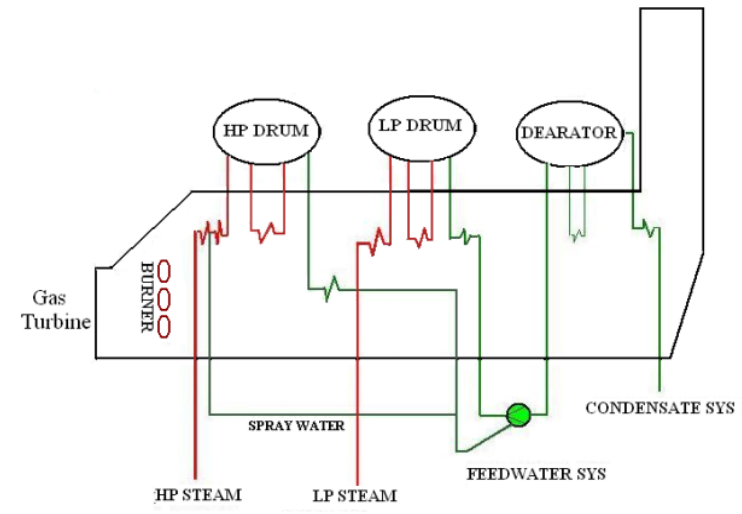

Fig. 1. The heat recovery steam generator boiler.

\section{HRSG MODELING}

In order to model the subsystems of HRSG, the input and output data of plant performances were recorded. Due to the lack of prior information from the performance of gas unit, the recorded data for the transient responses were collected with respect to the changes in fuel flow rate at auxiliary burners. The gas flow rate was considered as constant value for gas units. Two different data sets were prepared from the plant responses during load changed, which were used in the model training and model testing processes.

Dynamic systems can be divided into two categories: first group consists of systems that have only feedforward connections, and the others are systems with feedback or recurrent connections. If the output of the model at a moment is applied as its input at the next moment, the model is called dynamic or recurrent model. In other words, in recurrent models, the output of the model at the existing moment is influenced by the output of the model at previous moments. A dynamic fuzzy model can be developed by using the common NARX model topology as a discrete-time nonlinear mapping on some previous measured outputs and inputs as follows,

$$
\begin{array}{r}
y(k)=f\left(u(k), u(k-1), \ldots, u\left(k-n_{u}\right),\right. \\
y(k-1), \ldots, y\left(k-n_{y}\right)
\end{array}
$$

where $n_{u}$ and $n_{y}$ are the number of past terms for input $u$ and output $y$, respectively. Here, the non-linear mapping function $f(\cdot)$ is considered as a TSK type fuzzy system.
Neuro-Fuzzy System

The principle of ANFIS can be described by a set of if-then rules as follows [9],

$$
\begin{aligned}
& R_{i}: \text { if } x_{1} \text { is } A_{i, 1} \text { and ... and } x_{k} \text { is } A_{i, k} \\
& \text { then } y_{i}=b_{i, 0}+b_{i, 1} x_{1}+\ldots+b_{i, k} x_{k}
\end{aligned}
$$

where $A_{i, k}$ is the membership function associated with input variables $x_{k}$ and $N$ is the number of inputs

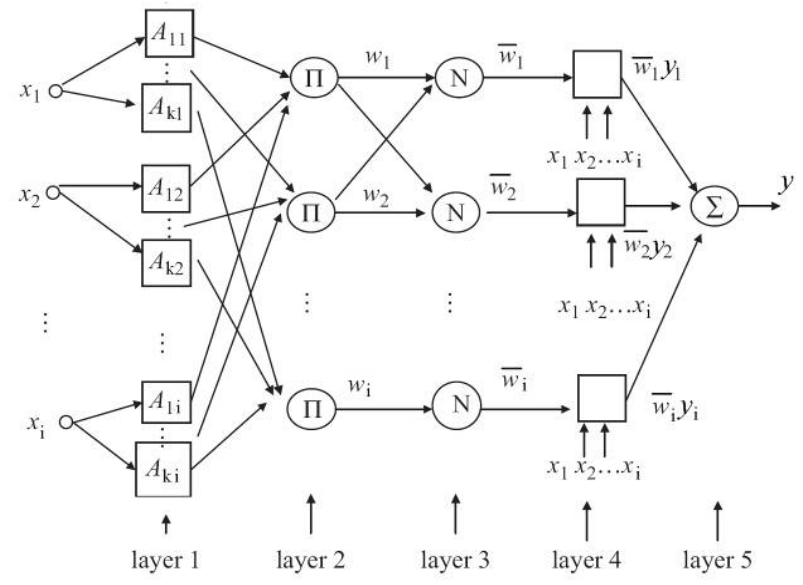

Fig. 2. The TSK anfis architecture.

In this structure, a linear combination of the input variables are considered as the conclusion functions of fuzzy rules. The firing degrees of the fuzzy rules are calculated through the five layers of the model [9].

Layer 1: Each node represents a linguistic label. Here, the membership function $A_{i, k}$ is considered to be Gaussian, which is specified by the center $v$ and the spread $\sigma$,

$$
A_{i, k}\left(x_{r}\right)=\exp \left(-\left(\left(x_{r}-v_{i, k}\right) / \sigma_{i, k}\right)^{2}\right)
$$

Layer 2: The fulfillment degree of rules are calculated by multiplying all incoming values as follows,

$$
w_{i}=\prod_{k=1}^{N} A_{i, k}\left(x_{k}\right)
$$

Layer 3: The relative degree of fulfillment of each rule is calculated by normalizing corresponding degree of fulfillment as follows,

$$
\bar{w}_{i}=w_{i} / \sum_{i=1}^{c} w_{i}
$$

Layer 4: The consequent of each rule is calculated by multiplying the corresponding rule in its relative degree of fulfillment as,

$$
\bar{y}_{i}=\bar{w}_{i} y_{i}
$$

Layer 5: The output of the net or the fuzzy system is calculated by adding all incoming weighted consequents,

$$
y=\sum_{i=1}^{c} \bar{y}_{i}
$$

As a result, all input-output patterns can be defined as below,

$$
Y_{M \times 1}=X_{M \times(c+1) N} \cdot \Theta_{(c+1) N \times 1}
$$


The parameters of the matrix $\Theta$ and membership functions should be adjusted based on the experimental data. In order to define the parameters of membership functions, the FCM algorithm is employed for partitioning the data set into $c$ predefined subsets. The data partitioning into clusters depends on similarity or dissimilarity of the members of each cluster that defines by the distance of data points from cluster centers [11].

By defining $D\left(v^{i}, x^{j}\right)$ as the distance between $v^{i}$ and $x^{j}$, where $\left\{v^{i}\right\} \subset R^{s}$ and $\left\{x^{j}\right\} \subset R^{s}$ are the vector of cluster centers and unlabeled data set, respectively. The following objective function has to be minimized in order to obtain the best possible solution.

$$
\text { Minimize: } \quad J_{m}(\mathrm{~A}, V)=\sum_{j=1}^{n} \sum_{i=1}^{c}\left(A_{i j}\right)^{m}\left(D_{i j}\right)^{2}
$$

where $A_{i j}$ is the membership of the $j$ th data point in the $i$ th cluster and the weighting exponent $m(1 \leq m<\infty)$ controls the degree of fuzziness of each cluster. Minimization of $J_{m}$ is performed by considering the following constraints on the membership values, which would lead to the optimal partition.

$$
\begin{aligned}
& \forall j=1 \ldots n, \forall i=1 \ldots c, \\
& \sum_{i=1}^{c} A_{i j}=1 \quad \text { and } \quad 0 \leq A_{i j} \leq 1
\end{aligned}
$$

The best possible positions of cluster centers and corresponding membership functions can be obtained using (6) and (7) through an iterative process.

$$
\tilde{v}_{i}=\sum_{j=1}^{n}\left(A_{i j}\right)^{m} x_{j} / \sum_{j=1}^{n}\left(A_{i j}\right)^{m}, \quad 1 \leq i \leq c
$$

and

$$
\tilde{A}_{i j}=1 /\left(\sum_{k=1}^{c}\left(D_{i j} / D_{j k}\right)^{2 /(m-1)}\right), \quad 1 \leq i \leq c, \quad 1 \leq j \leq n
$$

The iteration would be stopped if no further improvement was observed in $J_{m}(U, V)$. By defining the fuzzy membership functions and corresponding fuzzy rules, the parameters of consequent in Eq. (8) can be obtained by using recursive least square estimator as follows,

$$
\left\{\begin{array}{l}
P_{k+1}=P_{k}-\left(P_{k} x_{k+1} x_{k+1}^{T} P_{k}\right) /\left(1+x_{k+1}^{T} P_{k} x_{k+1}\right) \\
\theta_{k+1}=\theta_{k}+P_{k+1} x_{k+1}\left(Y_{k+1}^{T}-x_{k+1}^{T} \theta_{k}\right)
\end{array}\right.
$$

In the next section, the modeling approach is applied to different parts of HRSG boiler.

\section{Modeling AND Simulation}

In this section, the HRSG boiler is decomposed to smallest subsystems in order to ease the process of modeling the boiler. Each part can be presented by a multi-input single-output (MISO) FIS. The input-output data sets and the responses of the developed model for each section will be presented.

\section{A. Economizer}

Fig. 3 presents the schematic diagram of economizer recurrent neuro-fuzzy model. It is noted that the number of inputs in this model is 11 , if only 3 linguistic variables be assigned for each fuzzy input, the number of rules would be as $3^{11}$ rules. Using fuzzy $c$-mean clustering, the number of rules reduces to only 21 rules.

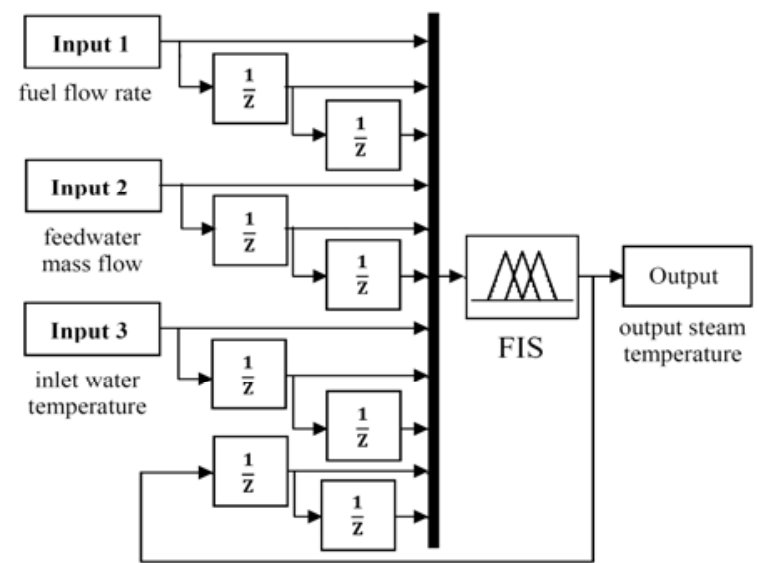

Fig. 3. The schematic of the neuro-fuzzy model for economizer.

The effective variables of the economizer output temperature are known as feedwater mass flow, fuel flow rate and input steam temperature and the output variable is the economizer temperature. The input/output vectors of the economizer model are summarized as follows:

$$
\begin{gathered}
\text { Input }=\left[\begin{array}{ccc}
\dot{m}_{\text {fuel }} & \dot{m}_{\text {feedwater }} & T_{\text {feedwater }}
\end{array}\right]^{T} \\
\text { Output }=\left[T_{\text {eco_out }}\right]^{T}
\end{gathered}
$$

where $T$ outside the bracket stands for "transpose". The responses of developed model for economizer section are compared with experimental data taken from real plant, which is shown in Fig. 4.

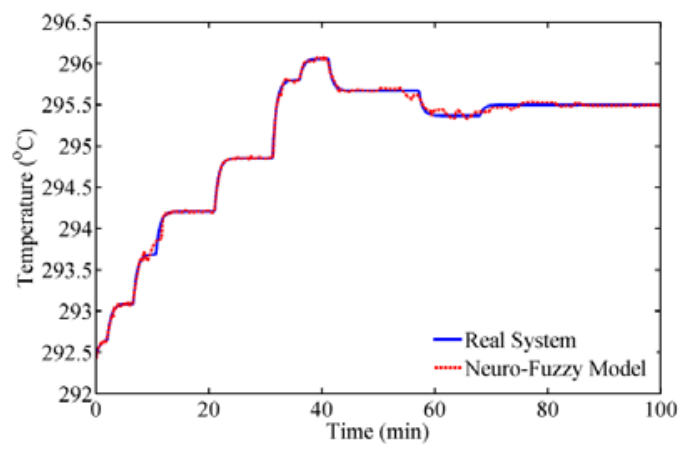

Fig. 4. Responses of economizer neuro-fuzzy model and actual plant.

\section{B. Drum}

The same structure that was used for the economizer section was employed with 14 inputs, and 25 rules were employed for the drum section. A schematic of drum section is presented in Fig. 5. As it is shown, the input feedwater and the output steam mass flow rates have the most effects on the dynamics of drum. The other input and output for this section are corresponded to evaporator section, which can be characterized by drum pressure and fuel flow rate. Consequently, the input/output vector for this section can be summarized as follows,

$$
\text { Input }=\left[\begin{array}{llll}
\dot{m}_{\text {feedwater }} & \dot{m}_{\text {steam_in }} & P_{\text {drum }} & \dot{m}_{\text {fuel }}
\end{array}\right]^{T}
$$


Output $=\left[L_{\text {drum }}\right]^{T}$

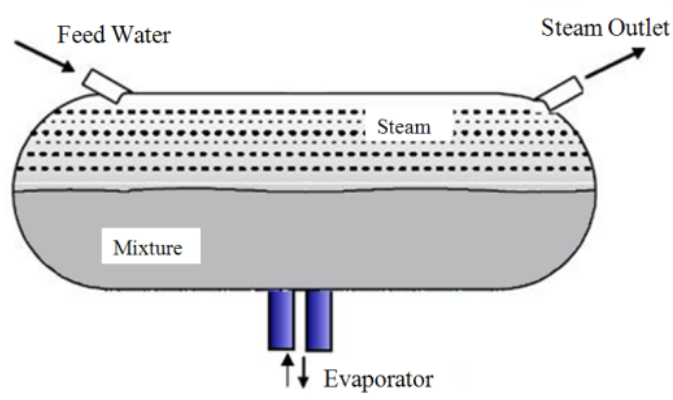

Fig. 5. The schematics of the drum section.

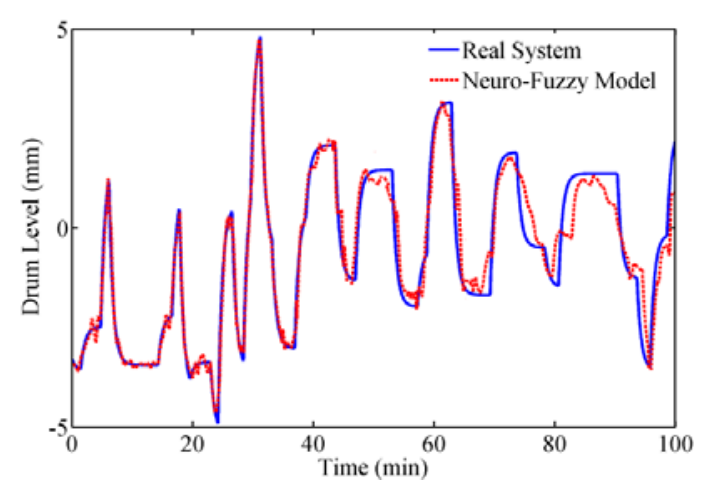

Fig. 6. Responses of drum neuro-fuzzy model and actual plant.

A comparison between the responses of the developed model and the responses of the real plants was performed. Obtained results are presented in Fig. 6, which validates the accuracy and performance of the modeling approach.

\section{Superheater}

For superheater section, a model with 11 inputs and 19 fuzzy rules are adequate to describe its dynamic behaviors. Fuel flow rate, input steam temperature and mass flow rate to the superheater section is considered as the main variables to predict the superheated output temperature. The input/output vectors of the superheater model are summarized as follows:

$$
\begin{gathered}
\text { Input }=\left[\begin{array}{lll}
\dot{m}_{\text {fuel }} & \dot{m}_{\text {steam_in }} & T_{\text {steam_in }}
\end{array}\right]^{T} \\
\text { Output }=\left[\begin{array}{l}
T_{\text {steam_out }} \\
]^{T}
\end{array}\right.
\end{gathered}
$$

In Fig. 7, the responses of the developed neuro-fuzzy model for superheater section are compared with actual plant responses.

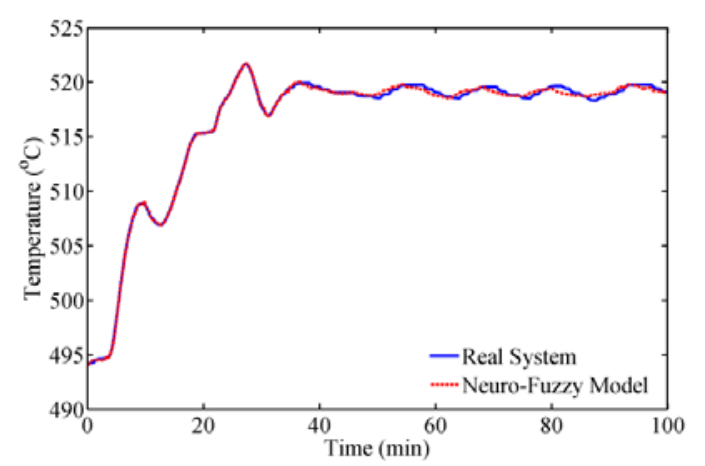

Fig. 7. Responses of the superheater section.

\section{De-Superheater}

In order to regulate the output temperature of the superheating sections, the de-superheaters are considered between two parts of superheater. By neglecting the pressure loss in the attemperator, the output temperature of the de-superheater can be estimated with respect to the inlet temperature and flow of superheated steam and temperature and flow of water spray. The number of inputs for this model is 14 and the number of fuzzy rules is equal to 21 . The input/output vector for the de-superheater section is as follows,

$$
\begin{aligned}
& \text { Input }=\left[\begin{array}{llll}
\dot{m}_{\text {spary }} & T_{\text {spary }} & \dot{m}_{\text {steam_in }} & T_{\text {steam_in }}
\end{array}\right]^{T} \\
& \text { Output }=\left[T_{\text {steam_out }}\right]^{T}
\end{aligned}
$$

Also, it is noted that $\dot{m}_{\text {steam } \_u t}=\dot{m}_{\text {steam_in }}+\dot{m}_{\text {spary. }}$ The responses of the developed model for the de-superheater are presented in Fig. 8.

In order to demonstrate the advantages of the proposed modeling approach, a comparison between the responses of the developed models and the responses of the recursive ANN models is carried out. The performances of the developed models are evaluated by calculating the error functions, where the error is defined as the difference between the predicted values by models and the experimental data. Here, the upper bound error $(\operatorname{Max}(|e|))$, lower bound error $(\operatorname{Min}(|e|))$, mean absolute error $(M A E)$ and correlation coefficient $\left(R^{2}\right)$ are calculated for both transient and steady state conditions over the operating range, which are presented in Table I to IV.

\begin{tabular}{|c|c|c|c|c|}
\hline & $\operatorname{Max}(|\mathrm{e}|)$ & $\operatorname{Min}(|e|)$ & MAE & $R^{2}$ \\
\hline ANFIS & 0.2057 & $6.9399 \mathrm{e}-6$ & 0.0229 & 0.9993 \\
\hline ANN & 0.1988 & $1.6403 \mathrm{e}-5$ & 0.0375 & 0.9981 \\
\hline \multicolumn{5}{|c|}{ TABLE II: ERROR FUNCTIONS FOR THE DRUM MODELS } \\
\hline & $\operatorname{Max}(|\mathrm{e}|)$ & $\operatorname{Min}(|e|)$ & MAE & $R^{2}$ \\
\hline ANFIS & 1.0560 & $1.1113 \mathrm{e}-4$ & 0.2618 & 0.9858 \\
\hline ANN & 1.7675 & $4.7787 \mathrm{e}-5$ & 0.3424 & 0.9707 \\
\hline
\end{tabular}

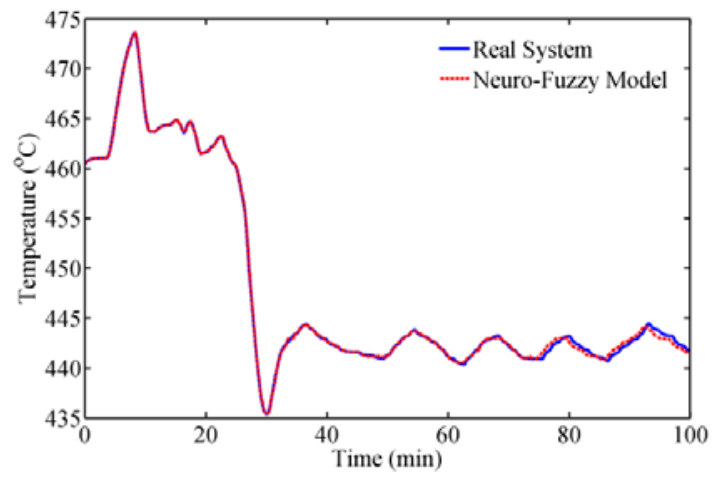

Fig. 8. Responses of de-superheater model.

TABLE I: ERROR FUNCTIONS FOR THE ECONOMIZER MODELS

TABLE III: ERROR FUNCTIONS FOR THE SUPERHEATER MODELS

\begin{tabular}{ccccc}
\hline \hline & $\operatorname{Max}(|\mathrm{e}|)$ & $\operatorname{Min}(|\mathrm{e}|)$ & $\operatorname{MAE}$ & $R^{2}$ \\
\hline ANFIS & 0.6807 & $3.8685 \mathrm{e}-6$ & 0.1526 & 0.9995 \\
ANN & 0.6450 & $2.1423 \mathrm{e}-5$ & 0.1756 & 0.9995 \\
\hline \hline
\end{tabular}


TABLE IV: ERROR FUNCTIONS FOR THE DE-SUPERHEATER MODELS

\begin{tabular}{ccccc}
\hline \hline & $\operatorname{Max}(|\mathrm{e}|)$ & $\operatorname{Min}(|\mathrm{e}|)$ & $\operatorname{MAE}$ & $R^{2}$ \\
\hline ANFIS & 0.7967 & $2.8952 \mathrm{e}-4$ & 0.1655 & 0.9998 \\
ANN & 0.8243 & $4.7876 \mathrm{e}-5$ & 0.2067 & 0.9997 \\
\hline \hline
\end{tabular}

Obtained results show the performance and feasibility of the modeling approach in terms of more accuracy and less deviation between the predicted values by the developed models and the experimental data.

\section{CONCLUSION}

This paper presents an application of neuro-fuzzy modeling approach in order to describe the nonlinear behavior of a heat recovery steam generator. The recurrent structure of TSK fuzzy system was chosen for this aim. A combination of fuzzy clustering techniques (FCM) and least square estimation was employed for adjusting the parameters of membership functions and the fuzzy rules, respectively. The responses of the developed models were compared with the experimental data in order to validate their accuracy. In addition, the performances of the developed models were compared with the performances of recurrent ANN models in order to show the feasibility of modeling approach. Obtained results indicate the accuracy and performance of the models in both transient and steady state conditions.

\section{REFERENCES}

[1] S. Lu and B. W. Hogg, "Dynamic nonlinear modeling of power plant physical principles and neural networks," Journal of Electrical Power and Energy Systems, vol. 22, pp.67-78, 2000.

[2] K. J. Astrom and R. D. Bell, "Drum-boiler dynamics," Automatica, vol. 36, pp. 363-378, 2000.

[3] A. Afzalian and D. A., Linkens, "Training of neuro-fuzzy power system stabilizers using genetic algorithms," International Journal of Electrical Power \& Energy Systems, vol. 22, pp. 93-102, 2000.

[4] A. Sanchez-Lopez, G. Arroyo-Figueroa, and A. Villavicencio-Ramirez, "Advanced control algorithms for steam temperature regulation of thermal power plants," International Journal of Electrical Power \& Energy Systems, vol. 26, pp. 779-785, 2004.

[5] J. Vieira, F. Morgado Dias, and A. Mota, “Artificial neural networks and neuro-fuzzy systems for modeling and controlling real systems: a comparative study," Engineering Applications of Artificial Intelligence, vol. 17, pp. 265-273, 2004.

[6] J. Zhang, M. Fei, K. Li, and Q. Zhu, "Fuzzy modeling of a medium-speed pulverizer using improved genetic algorithms," Lecture Notes in Computer Science, vol. 4113, pp. 1269-1274, 2006.

[7] A. Ghaffari, A. Chaibakhsh, and C. Lucas, "Soft computing approach for modeling power plant with a once-through boiler," Engineering Applications of Artificial Intelligence, vol. 20, pp. 809-819, 2007.

[8] R. Babuška and H. Verbruggen, "Neuro-fuzzy methods for nonlinear system identification," Annual Reviews in Control, vol. 27, pp. 73-85, 2003.

[9] J. R. Jang, “ANFIS: adaptive-network-based fuzzy inference," IEEE Transactions on Systems, Man, and Cybernetics, vol. 23, pp. 665-685, 1993.

[10] A. Chaibakhsh, N. Chaibakhsh, and M. B. Abdul Rahman, "Fuzzy modeling and optimization of biochemical processes: a case study". in Proc. International Conference on Chemistry and Chemical Engineering, vol. 1, 2010, pp. 11-15.

[11] G. Beliakov and M. King, "Density based fuzzy c-means clustering of non-convex patterns," European Journal of Operational Research, vol. 173, pp. 717-728, 2006.

Ali Ghaffari was born in 1948, received his B.Sc. degree in 1970 from Sharif University of Technology (in Tehran), M.Sc. degree in 1974 from Georgia Tech., and his Ph.D. degree in 1978 from Berkeley, all in Mechanical Engineering. He is a Professor with the Department of Mechanical Engineering at the K.N. Toosi University of Technology (Tehran) since 1987 . He teaches courses in the areas of automatic control, advanced and fuzzy control. His research interests are in the areas of control systems and biomechanics. He is one of the founders of the ARAS Research Center for Design, Manufacturing and Control of Robotic Systems, and Automatic Machineries.

Ali Chaibakhsh was born in 1980, received his B.Sc. degree in 2002 from University of Guilan in Mechanical Engineering, Rasht, Iran, and his M.Sc. and Ph.D. degrees in Mechanical Engineering in 2004 and 2009 from K.N. Toosi University of Technology, Tehran, Iran. He is now an Assistant Professor at the Department of Mechanical Engineering, University of Guilan. His research intersects are intelligent system including neural networks, fuzzy logic, and soft computing techniques and their applications in industrial processes modeling and control.

Sajjad Shahhoseini was born in 1985, received his B.Sc. and M.Sc degrees both in Mechanical Engineering, in 2008 and 2011 from South Tehran Brach, Islamic Azad University. His research intersects are in modeling and control of thermal power plants. 